\title{
Care of the Elderly Patient with Lower Extremity Amputation
}

\author{
Elise M. Coletta, $M D$
}

Background: The elderly patient with a lower extremity amputation (LEA) remains relatively common in most family medicine practices. LEA can be categorized into three major types: partial foot, transtibial amputation, and transfemoral amputation. Family physicians have not been well trained to provide care to these patients.

Methods: A literature review was performed using the key words "lower extremity amputation," "aged" and "rehabilitation."

Results and Conclusions: Appropriate medical, surgical, and rehabilitative care can have a positive effect on the functional outcome for an elderly patient with a lower extremity amputation. The family physician can be instrumental in preparing the patient and family for surgery, providing psychological support, preventing and treating complications, managing comorbid illness, and assisting in rehabilitation. In addition, the family physician is primarily responsible for the daily care needs of these patients. (J Am Board Fam Pract 2000;13:23-34.)

Despite improvements in medical and surgical limb salvage techniques, lower extremity amputation (LEA) remains a relatively common procedure. In 1993, 1,546,000 people in the United States were living with some form of major limb amputation. ${ }^{1,2}$ Of the 127,000 limb amputation procedures done in acute-care, nonfederal hospitals that year, 98,000 involved the lower extremity. ${ }^{1,2}$ The direct medical cost for a single LEA procedure is approximately $\$ 46,900 .^{3}$

\section{Methods}

A literature review was performed using the key words "lower extremity amputation," "aged" and "rehabilitation." In addition, I drew upon personal experience and that of local experts.

\section{Lower Extremity Amputation}

LEA is disproportionately a problem of older men; $75 \%$ of patients who undergo LEA are male., ${ }^{4,5}$ The incidence of LEA increases after age 55 years. ${ }^{6}$ Although the average age of a lower extremity am-

Submitted, revised, 7 July 1999.

From the Department of Family Medicine, Brown University School of Medicine Providence; and the Department of Gerontology, Memorial Hospital of Rhode Island, Pawtucket. Address reprint requests to Elise M. Coletta, MD, Memorial Hospital of Rhode Island, 111 Brewster St, Pawtucket, RI 02860. putee patient is 51 to 69 years, ${ }^{7}$ from 1910 to 1979 , the age-related incidence of LEA increased fourfold for persons older than 80 years. ${ }^{8,9}$ Despite medical and surgical advances in the treatment of the dysvascular limb, the overall incidence of LEA did not begin to decrease until the $1980 \mathrm{~s} .{ }^{8,9}$ Still, the absolute number of older adults living with LEA has increased because of the aging of the US population and the increasing incidence of peripheral vascular disease with age. 6,8

Diabetics have a 15 -fold higher risk for LEA. ${ }^{8,9}$ Risk factors for amputation among diabetic patients include older age, male sex, certain racial and ethnic groups, poor glycemic control, diabetes of longer duration, and poor preventive health care. ${ }^{10}$ The risk for amputation in diabetics has declined in the last few years, probably as a result of improved diabetic control, changes in patient lifestyle, and the increased use of limb salvage vascular surgery. ${ }^{9}$ Structured diabetes management programs have shown an overall reduction in subsequent LEA rate. ${ }^{3,10}$ One program, implemented in a primary care setting, showed a $48 \%$ reduction in LEA during a 3 -year period. ${ }^{3}$ Structured diabetes management programs systematically implement comprehensive diabetes care according to practice guidelines.

The morbidity and mortality related to LEA remains considerable. Operative mortality rates 
Table 1. Lower Extremity Amputation (LEA) in the Elderly Patient.

\begin{tabular}{lcccc}
\hline Type of LEA & $\begin{array}{c}\text { Percent of Total } \\
\text { Number of LEA }\end{array}$ & $\begin{array}{c}\text { Percent Recommended } \\
\text { for Prosthetic Gait } \\
\text { Training }\end{array}$ & $\begin{array}{c}\text { Percent Using Prosthesis } \\
\text { after Intensive Physical } \\
\text { Therapy Program }\end{array}$ & $\begin{array}{c}\text { Percent Additional Energy } \\
\text { Required for Normal } \\
\text { Bipedal Ambulation }\end{array}$ \\
\hline $\begin{array}{l}\text { Partial foot } \\
\text { Transtibial }\end{array}$ & 50 & $\begin{array}{c}\text { Not applicable } \\
60-80\end{array}$ & $\begin{array}{l}\text { Not applicable } \\
60-90\end{array}$ & 0 \\
$\begin{array}{l}\text { Transfemoral } \\
\text { or higher }\end{array}$ & 25 & $20-30$ & $0-40$ & Unilateral TTA: 40-60 \\
Bilateral TTA: 60-100 \\
Th-120
\end{tabular}

TTA-transtibial amputation.

Adapted from Cutson and Bongiorni ${ }^{6}$ and Andrews. ${ }^{11}$

range from $5 \%$ to $17 \%$ and postoperative (within 30 days) death rates vary from $2 \%$ to $23 \%{ }^{6,9}$ Worsened mortality figures are associated with a higher amputation level and diabetes. ${ }^{6,8,9}$ Age older than 80 years is also associated with decreased survival after amputation. ${ }^{6}$ The mean survival for a LEA patient is 2 to 5 years. ${ }^{9}$ The most frequent cause of death is cardiovascular disease. The incidence of ipsilateral reamputation ranges from $8 \%$ to $22 \%$, but might be decreasing as a result of improved surgical techniques and more appropriate initial choice of amputation level. ${ }^{6,8,9}$ The contralateral LEA rate within 4 years is $26 \%$ to $44 \% .{ }^{6,9}$ Most bilateral amputee patients have diabetes. ${ }^{11}$

\section{Pathogenesis}

Among older adults, vascular insufficiency, often with concomitant diabetes, accounts for approximately $75 \%$ of LEAs. ${ }^{2,9,11}$ Twenty percent of LEAs are done as a result of traumatic limb damage. ${ }^{2}$ Traumatic amputee patients tend to be younger and healthier than vascular amputee patients. ${ }^{12} \mathrm{Be}-$ nign or malignant tumors are responsible for the remaining $5 \%$ of amputations among older patients. $^{2}$

\section{Types of Amputation}

LEA can be categorized into three major types, partial foot, transtibial amputation, and transfemoral amputation (Table 1).

\section{Partial Foot Amputation}

Transmetatarsel and more distal foot amputations usually cause minor functional problems. ${ }^{13} \mathrm{Mid}-$ foot amputation procedures are not universally accepted because of the potential for equinus deformity, residual limb ulceration, and problems with prosthesis fitting. ${ }^{13}$ There are functional benefits, however, gained from retaining the calcaneus and preserving ankle motion. ${ }^{13}$ Ankle and hindfoot procedures are similarly controversial, except for a Syme amputation (disarticulation of the foot). ${ }^{13}$

\section{Transtibial Amputation}

Transtibial amputations are usually done at the junction of the upper and middle third of the tibia. For higher levels of transtibial amputation, it is usually better to preserve the knee joint, even if the remaining limb is short. ${ }^{14}$ The knee joint is very important for functional gait and dramatically de- 8 creases the energy expenditure of ambulation. ${ }^{6,7}$ As the level of LEA is higher, there is a progressive loss of proprioception and balance, leading to a less efficient and less functional gait. ${ }^{6}$ Preserving the knee is especially important for elderly amputee patients, because they will more often have comorbid disease that might limit their exercise potential or adversely affect their baseline gait. ${ }^{6}$

\section{Transfemoral Amputation}

In general, transfemoral amputation with residual limb must be at least 4 to 6 inches in length from the groin to fit a prosthesis, but success is also dependent on adequate soft-tissue volume. The number of transfemoral amputations has declined since the 1980 s. $^{9}$ This decline is probably due to improved surgical techniques, as well as better preoperative assessment of vascular status that more accurately determines the level of tissue viability. ${ }^{6}$

Table 1 contains a summary of the changes in $\stackrel{0}{\mathbb{D}}$ the energy demands (kilocalorie per meter) of ambulation with various amputation levels. These increased energy demands can preclude ambulation for a small subpopulation of amputee patients or $\stackrel{\mathbb{Q}}{\varnothing}$ limit ambulation distance for a greater number of patients. ${ }^{15}$ Most LEA patients compensate for the 
higher energy demands of ambulation by walking more slowly, so that their energy expenditure is not increased. Because of the extreme energy demands ( $>200 \%$ more than normal bipedal ambulation), only young, healthy, motivated bilateral transfemoral amputation patients have a high success rate for independent ambulation. ${ }^{6,9}$ For patients with concomitant comorbid disease, especially cardiac problems, the increased arm activity required for selfpropelling a wheelchair can be stressful to the heart. $^{8}$

\section{Rehabilitation Potential}

To estimate preoperative rehabilitation potential, it is important to establish the goals of the amputation procedure, estimate the functional prognosis, and select an appropriate site for rehabilitation. Depending on rehabilitation potential, the goal of LEA can vary from patient comfort only to restoration of an independent lifestyle.

To estimate rehabilitation potential, the family physician should assess the patient's overall medical condition, prognosis, cardiopulmonary reserve, cognitive and functional status, muscle strength, and the mobility of adjacent joints. Although being older than 80 years is associated with poorer rehabilitation outcomes, in general, comorbid illness, general health status, and level of amputation are more important than age in determining the outcome of rehabilitation. ${ }^{6,16}$

Barriers to successful rehabilitation include cognitive dysfunction that is severe enough to preclude training, severe neurologic impairment, irreducible knee or hip contracture, or comorbid disease (eg, congestive heart failure, angina, or chronic lung disease) that greatly impairs exercise tolerance. ${ }^{6}$ Patients with impaired cognition have lower levels of functional improvement after rehabilitation, but might still be able to achieve major functional improvements that are maintained with time and that increase the chance for a home discharge. ${ }^{17} \mathrm{~A}$ relative contraindication to gait training is vascular compromise of the contralateral extremity, which might worsen secondary to its increased weightbearing load postoperatively. ${ }^{6}$ Some experts, however, consider threatened gangrene of the contralateral limb an urgent indication for prosthetic training because of the increased risk of contralateral limb loss. ${ }^{11,14}$ No single comorbid illness will universally contraindicate a trial of rehabilitation.
Any amputee patient who has recently walked or has the potential to walk should be given an opportunity for rehabilitation in some setting. ${ }^{14}$

The medical, surgical, and rehabilitation care of the elderly amputee patient is complex because of the normal physiologic changes of aging, the common occurrence of comorbid disease, and the likelihood that the contralateral extremity is vascularly compromised. ${ }^{9}$ Decreases in muscle strength, bone density, and maximum oxygen consumption with aging, as well as the increased susceptibility of elderly patients to deconditioning and other medical problems with even short periods of immobility, can lead to a more complicated postoperative and rehabilitative course. ${ }^{6,18}$ Four percent to $29 \%$ of elderly amputee patients have had a stroke either before or subsequent to their amputation. ${ }^{19}$ In addition, approximately $40 \%$ of elderly amputee patients have arthritis, and $20 \%$ to $30 \%$ have some impairment in hearing or vision. ${ }^{11}$ Fifteen percent to $20 \%$ have overt heart disease, but many more have underlying asymptomatic coronary disease that might first come to medical attention during the rehabilitation phase of recovery when the elderly patient has progressed to a more physically taxing level of exercise. ${ }^{1,20}$ More than $5 \%$ of elderly amputee patients also have cognitive dysfunction that could increase the chance of postoperative delirium. ${ }^{11}$ Overall, elderly patients are more likely to develop postoperative medical problems (eg, congestive heart failure, stroke) that affect ultimate recovery. ${ }^{6}$

\section{Stages of Care}

The stages of care for an LEA patient are outlined in Tables 2 and 3. The family physician should be involved in almost all these stages of care and will have the primary role providing ongoing care to these patients.

\section{Preoperative}

An elderly patient with an imperiled limb often has other chronic medical problems that make the risk of surgical complications relatively high. As a result, the decision to first offer time-consuming, possibly unsuccessful, limb salvage surgery becomes very complex. Overall, vascular bypass surgery seems to reduce the incidence of subsequent lower extremity amputation, but a failed vascular procedure does predict a need for a higher level of 
General aspects

Residual limb care

Prosthesis care

Sexual function

Psychological issues

Preventive care of contralateral lower extremity
Regular assessment of patient's functional level and functioning of prosthesis

Aggressive treatment of comorbid medical conditions

Adequate nutrition and maintenance of consistent weight

Inspect residual limb daily for abrasions, reddened areas

Cleanse daily with gentle soap and tepid water and pat dry

Massage scar

Discourage shaving of leg

Apply thin layer of bland emollient cream if skin is dry

Wash prosthetic socks or sheath daily with gentle detergent. Rinse and dry well

Wipe socket daily with damp cloth

Inspect socket and prosthesis daily for cracks or instability

Initiate discussion

Determine the couple's attitudes and beliefs

Educate regarding any expected changes in functioning

Provide information to deal with balance or movement problems

Lifelong emotional support

Monitor for depression, social isolation

Daily skin inspection for abrasions, ulcers

Professional nail and corn and callus care

No chemical abrasives (eg, corn plasters)

Treat fungal infections promptly

Use only an electric razor to shave the leg

Proper skin care (wash foot daily with gentle soap and tepid water. Apply thin layer of bland emollient for dry skin)

Protect leg from excessive heat, cold, moisture, or trauma (eg, wear warm footwear in winter, no prolonged soaking of feet, avoid walking barefoot)

Obtain appropriate footwear (well-fitting with extra depth and width of toe box)

Inspect shoe before donning to remove retained debris. Do not wear shoe with torn or roughened areas

Gradually and slowly increase wearing time for new shoes

Adapted from Leonard and Meier, ${ }^{2}$ Esquenazi and Meier, ${ }^{7}$ and McArelly and Faulkner. ${ }^{24}$

subsequent amputation. ${ }^{9}$ After the decision for amputation is made, the surgeon must make an assessment of the appropriate surgical level that will insure tissue viability while addressing functional concerns. The challenge in initial choice of amputation level is to weigh the potential need for a surgical revision against the functional benefit of a lower amputation level that preserves the knee. Clinical limb assessment, noninvasive tests (eg, ankle-brachial Doppler index or segmental lower extremity pressures) and lower extremity arteriography can be informative. ${ }^{21}$ An ankle-brachial Doppler index ratio of greater than 0.5 is associated with a greater than $90 \%$ success rate for healing a transtibial amputation. ${ }^{21}$ A ratio of less than 0.35 is associated with a poor prognosis for healing a toe amputation. ${ }^{21}$ Diabetic patients can have a spuriously high ankle-brachial pressure index despite considerable large- and small-vessel disease. ${ }^{21} \mathrm{~A}$ popliteal artery segmental occlusion pressure of greater than $50 \mathrm{~mm} \mathrm{Hg}$ is associated with successful healing of a transtibial amputation. ${ }^{21}$ Despite the above tests, the final decision on amputation level can be made at surgery, where the amount of blood flow to tissues can be observed.

The family physician should play a major role in all other aspects of preoperative care. Control of comorbid medical illnesses preoperatively will decrease subsequent mortality figures. ${ }^{21}$ Preoperative psychologic support is one of the most important roles for the family physician (Table 4). A patient's reaction to an anticipated limb amputation is related to age, sex, type of amputation planned, expectation of the success of rehabilitation, and the patient's perception of the functional value of the lost limb. ${ }^{5}$ Body image concerns might be less important for elderly amputee patients. ${ }^{5}$ In addition, the patient's premorbid personality and coping skills, previous losses, the amount and quality of social support, occupational and vocational de- 
Table 4. Preoperative Psychological Support.

Discuss possible need for an amputation early in course of illness

Encourage family involvement

Clarify surgeon's information by providing data at an appropriate pace and educational level for the patient and family

Review treatment provided to try to preserve the limb

Reinforce potential for the operation to improve function and quality of life while avoiding false optimism

Help patient focus on the need for surgery

Encourage patient or caregiver to express fears and concerns

Discuss statements of self-blame

Identify anger, grief, and depression

Challenge heroic cheerfulness

Reinforce continuity of patient's personal characteristics

Elicit patient's coping reaction during past crises

Explore strategies to accommodate postamputation work, lifestyle, recreational needs

Adapted from Butler et al. ${ }^{5}$

mands, as well as the type and degree of comorbid illness, are important. ${ }^{5}$ The supportive counseling initiated by the family physician in the preoperative period should be continued throughout the patient's operative, rehabilitative, and chronic care.

Preoperative physical therapy is helpful to prevent joint contracture and improve balance and muscle strength in the remaining limb. ${ }^{7,8}$ Full range of motion of the more proximal joints of the affected limb is especially important to maximize postoperative mobility. ${ }^{7}$ A preventive care plan for the remaining limb should be established because it will usually be at risk for ulceration and amputation also.

\section{Operative}

At surgery, attention is paid to appropriate softtissue coverage of the residual limb and placement of the suture line away from bony prominences so that the remaining limb will better tolerate a prosthesis. ${ }^{7}$ A semirigid residual limb dressing (eg, Unna dressing) that is fabricated and applied at surgery or in the recovery room can decrease postoperative residual limb edema, healing time, and pain, and it can aid in shaping the residual limb and protect the new incision against traumatic damage. $2,9,22$

\section{Acute Postoperattve Care}

Epidural medication for patient-controlled analgesia usually provides better postoperative pain con- trol. ${ }^{7}$ Phantom limb sensations are typical soo $\frac{1}{3}$ after surgery and do not necessarily require treatto ment. ${ }^{7}$

Initial elevation of the residual limb reduces the development of edema that can cause pain an delay healing. ${ }^{7,23}$ Beyond the first 2 days, howeve continued limb elevation can lead to a hip flexion contracture that could affect future mobility. Sim $\overrightarrow{\bar{\sigma}}$ ilarly, placing a pillow under the patient's back o. thigh can lead to a hip flexion contracture. ${ }^{24} \frac{\bar{p}}{\frac{p}{\infty}}$ pillow placed between the patient's legs can lead to a hip abduction contracture. ${ }^{24}$ Beginning on postes operative day 1 , the patient should be asked to lie prone to prevent a hip flexion contracture. Earlig mobilization will reduce the development of orthof static hypotension. ${ }^{7,18}$

Rehabilitation efforts must be continued imme diately after surgery to prevent muscle weakness, $\overrightarrow{\vec{\omega}}$ orthostasis, contracture, and other immobility-reî. lated medical problems. ${ }^{8,18}$ An overall medical plaiq to guard against immobility-related problems (ie, deep venous thrombosis, deconditioning) should be implemented. ${ }^{18}$

\section{Preprosthetic Phase}

The preprosthetic phase of rehabilitation include continued attention to wound healing and appros priate control of residual limb pain. Enhancing the patient's nutritional status and treating comorbicis medical conditions will improve wound healing. In addition to the aforementioned aspects of residua limb care, the patient should be taught mobiliza tion of the suture line, which will decrease adhe sions and desensitize the residual limb. ${ }^{6,14}$ Contin ued use of a semirigid residual limb dressing or th compressive elasticized cloth wrap dressing will re $\frac{\overline{7}}{3}$ duce edema and begin to shape the residual limb ing anticipation of fitting a prosthesis. ${ }^{22}$ Many refer ences contain specific instructions for wrapping the residual limb. ${ }^{4}$ These dressings can slip when the patient moves and require reapplication severa times a day to maintain appropriate positioning and compression. ${ }^{22}$ An elastic shrinker stocking can bêّ used after the sutures are removed. ${ }^{14,25}$ Typicall sutures are removed 3 to 4 weeks after surgery.

Positioning the patient is important in the preprosthetic phase. A leg board placed under the amputated limb will prevent a knee flexion contrac $\frac{\mathbb{D}}{\pi}$ ture and reduce dependent edema. ${ }^{4}$ Patients who are unable to lie in a prone position should lie supine and actively extend their amputated limbô 
while flexing the other leg. ${ }^{24}$ Physical therapy at this stage is progressive. Early training in safe and independent wheelchair mobility will improve a patient's outlook and restore the locus of control. ${ }^{11}$ Timely, appropriate rehabilitation is essential to enhance functional status within the remaining lifespan of the elderly amputee patient. ${ }^{6}$ Coordinated or dedicated multidisciplinary teams can definitely improve rehabilitation outcomes. ${ }^{6,8}$ The rehabilitation program for a geriatric amputee patient should be individualized according to the patient's health, physical status, functional status, motivation, and support systems. ${ }^{11}$ For the patient whose amputation was the result of vascular compromise, the preprosthetic phase of recovery typically lasts 6 to 10 weeks. $^{2}$

\section{Prosthesis Prescription}

Recent changes in prosthesis design and the use of ultralight materials have enhanced amputee function. $^{1,7,15}$ Factors relevant to the prosthesis prescription include the patient's general health, abilities, cognitive status, living arrangement, vocational and recreational needs, level of amputation, and the condition of the residual limb. ${ }^{1,9} \mathrm{~A}$ great variety of prosthetic components, socket fabrication techniques, and prosthesis suspension systems are available. ${ }^{7}$ A prosthesis is prescribed by a rehabilitation medicine physician.

A patient with a partial foot amputation requires a shoe filler (usually of sponge rubber or foam), shoe modification, or a slipper-type prosthesis according to the type or level of amputation performed. ${ }^{2,24}$ Figure 1 displays the most common transtibial and transfemoral amputation prostheses. Because the prosthesis is adjusted to a particular heel height, the patient should be instructed always to wear shoes of similar heel height. ${ }^{4}$

\section{Prosthetic Training}

A permanent prosthesis is prescribed after a period of ambulation on a temporary device. The goal of prosthetic training is gradually to improve prosthesis wearing time and functional use. Initially the prosthesis should be worn for only 15 to 20 minutes a day. Full-time use will require a minimum of several weeks of training. ${ }^{2}$ An elderly patient with an amputation will often require a gait aid for ambulation. If a cane is prescribed, it should be held in the hand contralateral to the prosthesis. It is

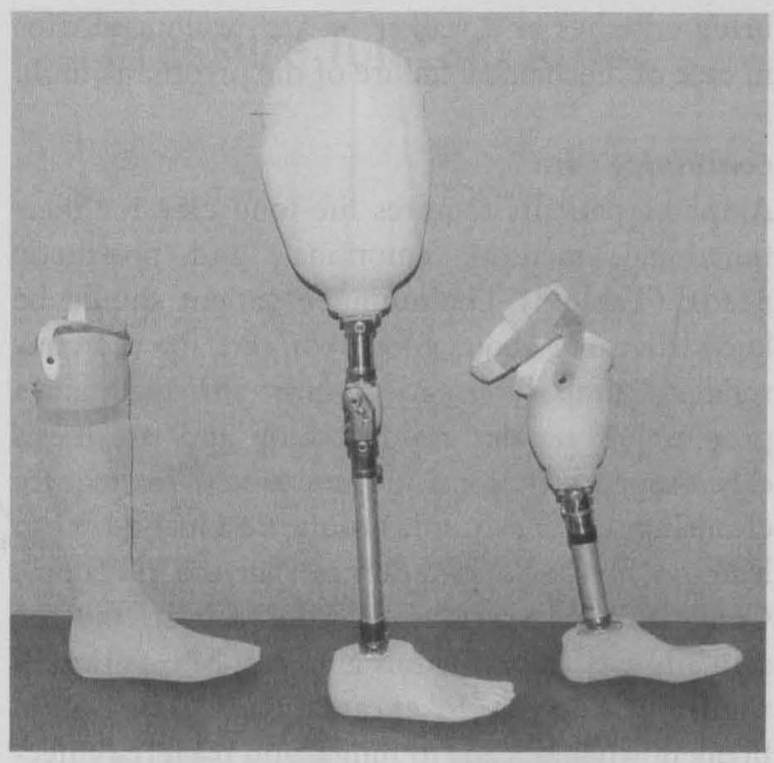

Figure 1. Right to left. Temporary transtibial amputation prosthesis: total contact patellar tendonbearing (PTB) socket with supracondylar cuff attachment. Temporary transfemoral amputation prosthesis: quadrilateral socket with suction suspension system. Permanent transtibial amputation prosthesis: PTB socket with supracondylar strap attachment. (Courtesy of Carlow Orthopedic and Prosthetic, Warwick, Rhode Island).

important not to set lower goals for gait training because a patient is elderly. ${ }^{7}$

Factors associated with successful prosthetic use include good general medical condition, a lower level of amputation, good muscle coverage of the residual limb, nontraumatic operative technique, and absence of residual limb pain. ${ }^{9,11}$

\section{Community Integration and Vocational Rebabilitation}

Depending on the study quoted and the level of LEA, from $20 \%$ to $80 \%$ of elderly patients return home after LEA rehabilitation. ${ }^{6}$ Independence in activities of daily living is a key factor for a successful home discharge. ${ }^{9}$ Although the amputee patient might return home, poor mobility in the community and difficulty reintegrating into work and recreational activities often occur. ${ }^{26}$ Possible social isolation is a particular concern with elderly patients. Specialized instruction and automobile modifications are required for the patient to resume driving. ${ }^{27}$ The patient should be instructed to 
bring crutches or a walker on any prolonged trips in case of mechanical failure of the prosthetic limb.

\section{Continuing Care}

Amputee patients requires life-long care for their functional, medical, emotional, and prosthetic needs. (Table 3) The amputee patient should be knowledgeable about good foot care for the contralateral limb. The patient must also maintain a program of regular residual limb and prosthesis care. Appropriate local hygiene is key. Inadequate cleansing in the skin folds of the residual limb can lead to mechanical irritation and surface infections. Conversely, overzealous cleansing can dry out the skin and cause eczematous changes. Maceration of the skin within the socket can also cause the skin to break down and leads to fungal and bacterial infections. Cornstarch, unscented talc, or an antiperspirant can control excessive moisture.

Prosthetic socks are often used at the interface of the limb and the socket of the prosthesis to adjust for physiologic volume changes throughout the day. ${ }^{7}$ Natural fiber materials will absorb local moisture. The sock must be pulled free of wrinkles and the seam positioned away from any bony prominence or scars before donning the prosthesis. Unless the patient wears the prosthesis consistently, an elastic shrinker stocking should be worn to maintain proper pressure and control local swelling.

An often unattended need of amputee patients is attention to sexual concerns. The LEA patient might interpret silence on this subject as a sign of prohibition. The patient's overall health and the couple's previous attitudes, beliefs, and experiences should be elicited. Amputee patients should be told that they might expend slightly more energy during intercourse, which could result in mild fatigue. ${ }^{28}$ Phantom limb pain can also occur with orgasm. ${ }^{24}$ The rehabilitation physician or the physical or occupational therapist can provide helpful information if the patient's balance or movement during sexual intercourse causes problems. Psychologic issues affecting sexual function include an altered body image, depression, and anxiety about disease progression.

\section{Pbysician Follow-up}

Because of frequent changes in the size and shape of the residual limb within the first 6 to 18 postoperative months, the patient should return to the rehabilitation physician during this time for any socket adjustment needed. Otherwise, yearly fo low-up visits are recommended.

The family physician should also attend to issues relating to the LEA during continuity care visits़ु, The frequency of visits to the family physician $\bar{R}$ often dictated by the care needs of any comorbid medical disease, but they should usually be no lesडे often than every 6 months. Aggressive treatment comorbid medical conditions, such as diabetes an arthritis, is important to prevent deterioration of the residual limb. ${ }^{27}$ It is important that the patien maintain a consistent body weight, because $\$$ change of as little as 5 pounds can lead to poot socket fit. ${ }^{4,11}$ A poorly fitting socket can lead to skitu irritation and breakdown and cause local pain. 柋 The family physician should inquire about residua limb or phantom limb pain, especially if the forme occurs with ambulation. Precise localization of the pain can help to focus subsequent physical exami nation. The family physician should also inquire about any problems with prosthesis fit or function. The occurrence of any falls, along with the circums stances, might highlight prosthesis problems. $\frac{A \bar{\phi}}{2}$ each visit, the patient's functional status and mor bility should be documented, and potential reasong for any deterioration explored.

Both of the patient's lower limbs should be in spected for skin abnormalities, especially areas o redness or ulceration. The scar on the residual limp should be mobilized to ensure movement in a directions. Adherent scars can become a source of pain. Any erythematous or painful areas should be palpated. For the transtibial residual limb, there are pressure-tolerant and pressure-sensitive areas (Fig ure 2). Localized pain, tenderness, or erythema over a pressure-sensitive area requires a visit to the rehabilitation physician, because there could be problem with prosthesis fit. Because of the differing anatomy, there are no similar high-risk pressure areas on the transfemoral residual limb. Next, the prosthesis should be examined for cracks or insta을. bility. The average life expectancy of a prosthesis is 3 to 5 years. $^{2}$ Finally, the physician should watch the patient ambulate. Malalignment or other pros thesis problems can cause limb pain and recurren skin breakdown and affect the balance, stability and efficiency of gait. ${ }^{15}$

\section{Problems with the Residual Limb}

Changes in the residual limb or prosthesis cart cause or contribute to multiple long-term patien 


\section{Pressure Sensitive Areas}

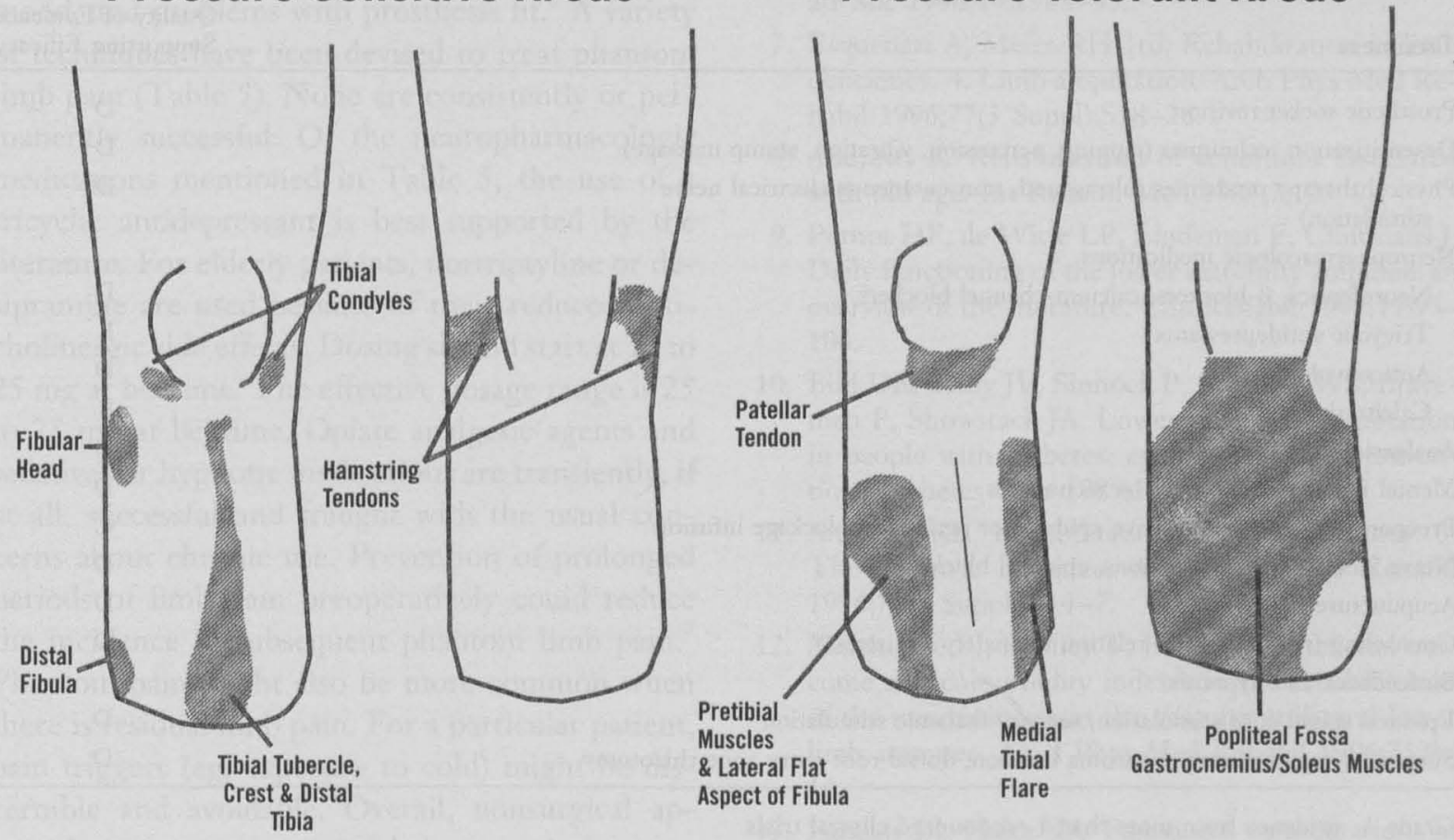

Figure 2. Pressure-sensitive and pressure-tolerant areas of the transtibial residual limb.

problems, including residual limb pain, phantom limb pain, neuroma formation, choke syndromes, skin irritation or breakdown, skin lesions, and gait abnormalities. $^{1}$

\section{Residual Limb Pain}

Causes of residual limb pain include skin irritation, infection or ulcer, underlying osteomyelitis or osteophyte, limb ischemia, neuroma, epidermoid cyst, a poorly fitting prosthesis, sensitive scar, and reflex sympathetic dystrophy. ${ }^{7,27,29}$ Persistent or late-onset residual limb pain can be secondary to all the causes of pain mentioned above. Palpation over a neuroma, a common cause of late-onset residual limb pain, will characteristically elicit lancinating discomfort. Neuromas can be treated surgically or with a local injection of an anesthetic-steroid mixture. ${ }^{7}$ Socket adjustment might be necessary.

\section{Skin Irritation or Breakdown}

A contact or allergic dermatitis can develop from the materials used in the socket liner or soap residue left on the liner. Chronic ulcers of the residual limb can be the consequence of persistent edema, bacterial infection, vascular disease, or localized pressure from an ill-fitting prosthesis. ${ }^{25}$ Malignant change can occur in these chronic ulcerations, and recurrent ulcers could lead to scarring that affects socket fit. ${ }^{25}$ The patient should contact their physician and not wear their prosthesis if irritation or ulceration develops.

\section{Skin Infection}

The skin of the residual limb contains many more bacteria than normal, and resistance to infection is lowered by local skin irritation. In addition, the skin within the prosthesis is always somewhat moist, which can lead to increased bacterial and fungal growth. Excessive heat and humidity, poor hygiene, uncontrolled diabetes, and poor prosthesis fit are all associated with an increased likelihood of local infection. ${ }^{25}$ Infection can occur as an area of cellulitis, superficial crusting pyoderma, folliculitis, or furuncle. Skin infection in the residual limb can require oral or parenteral antibiotics depending on severity and response to therapy. Bacterial infection is usually caused by coagulase-positive staphylococci or $\beta$-hemolytic streptococci; therefore, an antistaphylococcal penicillin or first-generation cephalosporin is an appropriate antibiotic choice. A furuncle requires warm compresses and incision and drainage. Fungal infections require extended 
Treatment

Prosthetic socket revision

Desensitization techniques (tapping, percussion, vibration, stump massage)

Physical therapy modalities (ultrasound, transcutaneous electrical nerve stimulation)

Neuropharmacologic medications

Neuroleptics, $\beta$-blockers, calcium-channel blockers

Tricyclic antidepressants

Anticonvulsants

Calcitonin

Analgesic medications

Mental imaging and relaxation techniques

Preoperative and postoperative epidural or perineural blockage infusion

Nerve blocks, steroid injections, epidural blocks

Acupuncture

Counseling (recognition of relation to anxiety and stress)

Biofeedback and hypnosis

Epidural spinal cord stimulation, sensory thalamic stimulation

Surgery: sympathectomy, neuroma excision, dorsal root entry zone rhizotomy

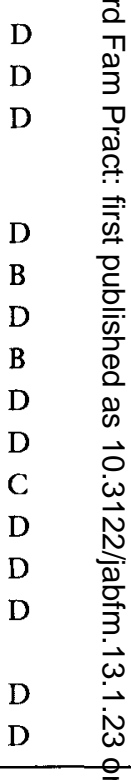

Grade A: evidence from more than 1 randomized clinical trials

B: evidence from clinical trial and/or more than 1 nonrandomized studies

C: evidence from 1 nonrandomized study and/or conflicting evidence with the majority of evidence supporting efficacy

D: common practice with no well-conducted studies supporting efficacy

Adapted from Esquenazi and Meier, ${ }^{7}$ Panerai et al, ${ }^{30}$ Jaeger and Maier, ${ }^{31}$ Patterson, ${ }^{32}$ Bach et al, ${ }^{33}$ Nikolajsen et al, ${ }^{34}$ and Hordso

periods of treatment with fungicidal creams or powders or, in severe or recurrent cases, with oral antifungal agents.

\section{Skin Lesions}

Epidermoid cysts develop from persistent frictional damage and are usually found at the margin of the prosthesis. Treatment is incision and drainage and avoidance of prosthesis use until the lesion is healed. The prosthesis will likely need to be refit. The patient should be referred promptly to the rehabilitation physician for any recurrent or chronic skin problems as seemingly minor abnormalities can, with inattention or mistreatment, develop into problems that could imperil future ambulation.

\section{Cboke Syndrome}

A choke syndrome is a potentially serious cause of residual limb pain that should be detected. If the prosthetic socket fits tightly around the proximal residual limb, but the distal residual limb is not in good socket contact, there will be obstruction of venous outflow, and distal limb edema will develop.
If unchecked, erythema, induration, and eventiol skin breakdown ensues. ${ }^{2}$ Treatment is a socket $\overrightarrow{\mathrm{E}}$ vision.

\section{Pbantom Pain}

Phantom limb discomfort should be differentiat鹿 from residual limb pain. Phantom limb pain often described as knifelike, burning, aching squeezing, or similar to the pain felt in the ischenfic limb preoperatively. ${ }^{4}$ Phantom limb pain should $\overrightarrow{\mathrm{Be}}$ differentiated from phantom limb sensation, whi⿺辶寸 is the feeling that all or part of the missing limbois still present. This later sensation is felt by mogt amputee patients and is usually mild and transiegt. A patient with phantom limb sensation should i vest in a night-light to decrease the chance of injury secondary to an attempt to ambulate on a none istent extremity.

Far fewer patients have phantom limb pain tha becomes physically, functionally, and emotionalty debilitating. Phantom limb pain persisting for mofe than 6 months will likely be chronic and difficult fo treat. ${ }^{7}$ The cause of phantom limb pain is not precisely known. ${ }^{24}$ The perceived intensity 
phantom limb pain is related to anxiety level, mood, and problems with prosthesis fit. ${ }^{7}$ A variety of techniques have been devised to treat phantom limb pain (Table 5). None are consistently or permanently successful. Of the neuropharmacologic medications mentioned in Table 5, the use of a tricyclic antidepressant is best supported by the literature. For elderly patients, nortriptyline or desipramine are used because of their reduced anticholinergic side effects. Dosing should start at 10 to $25 \mathrm{mg}$ at bedtime. The effective dosage range is 25 to $75 \mathrm{mg}$ at bedtime. Opiate analgesic agents and sedatives or hypnotic medications are transiently, if at all, successful and fraught with the usual concerns about chronic use. Prevention of prolonged periods of limb pain preoperatively could reduce the incidence of subsequent phantom limb pain. ${ }^{7}$ Phantom pain might also be more common when there is residual limb pain. For a particular patient, pain triggers (eg, exposure to cold) might be discernible and avoidable. Overall, nonsurgical approaches are more successful than surgical procedures. $^{7}$

In summary, the family physician can help prepare the LEA patient for surgery, provide psychological support, prevent and treat complications, manage comorbid illness, assist in rehabilitation, and attend to chronic care needs. The relatively short long-term survival of amputee patients heightens the need for aggressive medical and rehabilitative care to enhance the quality of the patient's remaining years.

\section{References}

1. Leonard JA Jr, Esquenazi A, Fisher SV, Hicks JE, Meier RH 3rd, Nelson VS. Prosthetics, orthotics, and assistive devices. 1. General concepts. Arch Phys Med Rehabil 1989;70(5 Suppl):S195-S201.

2. Leonard JA Jr, Meier RH 3rd. Upper and lower extremity prosthetics. In: DeLisa JA, editor. Rehabilitation medicine. Principles and practice. 3rd ed. Philadelphia: Lippincott-Raven, 1998.

3. Rith-Najarian S, Branchaud C, Beaulieu O, Gohdes D, Simonson G, Mazze R. Reducing lower-extremity amputations due to diabetes. Application of the staged diabetes management approach in a primary care setting. J Fam Pract 1998;47:127-32.

4. Yetzer E. Helping the patient through the experience of an amputation. Orthop Nurs 1996;15:45-9.

5. Butler DJ, Turkal NW, Seidl JJ. Amputation: preoperative psychological preparation. J Am Board Fam Pract 1992;5:69-73.

6. Cutson TM, Bongiorni DR. Rehabilitation of the older lower limb amputee: a brief review. J Am Geriatr Soc 1996;44:1388-93.

7. Esquenazi A, Meier RH 3rd. Rehabilitation in limb deficiency. 4. Limb amputation. Arch Phys Med Rehabil 1996;77(3 Suppl):S18-28.

8. Andrews K. Rehabilitation of conditions associated with old age. Int Rehabil Med 1985;7:125-9.

9. Pernot HF, de Witte LP, Lindeman E, Cluitmans J. Daily functioning of the lower extremity amputee: an overview of the literature. Clin Rehabil 1997;11:93106.

10. Bild DE, Selby JV, Sinnock P, Browner WS, Braveman P, Showstack JA. Lower-extremity amputation in people with diabetes: epidemiology and prevention. Diabetes Care 1989;12:24-31.

11. Andrews KL. Rehabilitation in limb deficiency. 3. The geriatric amputee. Arch Phys Med Rehabil 1996;77(3 Suppl):S14-7.

12. Melchiorre PJ, Findley T, Boda W. Functional outcome and comorbidity indexes in the rehabilitation of the traumatic versus the vascular unilateral lower limb amputee. Am J Phys Med Rehabil 1996;75:914.

13. Parziale JR, Hahn KA. Functional considerations in partial foot amputations. Orthop Rev 1988;17: 262-6.

14. Penington G, Warmington S, Hull S, Freijah N. Rehabilitation of lower limb amputees and some implications for surgical management. Aust NZ J Surg 1992;62:774-9.

15. Czerniecki JM. Rehabilitation in limb deficiency. 1. Gait and motion analysis. Arch Phys Med Rehabil 1996;77(3 Suppl):S3-8.

16. Leung EC-C, Rush PJ, Devlin M. Predicting prosthetic rehabilitation outcome in lower limb amputee patients with the functional independence measure. Arch Phys Med Rehabil 1996;77:605-8.

17. Resnick B, Daly MP. The effect of cognitive status on outcomes following rehabilitation. Fam Med 1997;29:400-5.

18. Coletta EM, Murphy JB. The complications of immobility in the elderly stroke patient. J Am Board Fam Pract 1992;5:389-97.

19. O'Connell PG, Gnatz S. Hemiplegia and amputation: rehabilitation in the dual disability. Arch Phys Med Rehabil 1989;70:451-4.

20. Williams LS, Lowenthal DT. Clinical problem-solving in geriatric medicine: obstacles to rehabilitation. J Am Geriatr Soc 1995;43:179-83.

21. Sarin S, Shami S, Shields DA, Scurr JH, Smith PD. Selection of amputation level: a review. Eur J Vasc Surg 1991;5:611-20.

22. Edelstein JE. Preprosthetic management of patients with lower-or upper-limb amputation. Phys Med Rehabil Clin North Am 1991;2:285-97.

23. Mikulaninec CE. An amputee critical path. J Vasc Nurs 1992;10:6-9. 
24. McAnelly RD, Faulkner VW. Lower limb prostheses. In: Braddom RL, editor. Physical medicine and rehabilitation. Philadelphia: WB Saunders, 1996.

25. Levy SW. Amputees: skin problems and prostheses. Cutis 1995;55:297-301.

26. Nissen SJ, Newman WP. Factors influencing reintegration to normal living after amputation. Arch Phys Med Rehabil 1992;73:548-51.

27. Chadwick SJ, Wolfe JH. ABCs of vascular diseases. Rehabilitation of the amputee. BMJ 1992;304: 373-6.

28. Shell J. Sexual rehabilitation of the amputee. Oncol Nurs Forum 1989;16:105-6.

29. Isakov E, Susak Z, Korzets A. Reflex sympathetic dystrophy of the stump in below-amputees. Clin J Pain 1992;8:270-5.

30. Panerai AE, Monza G, Movilia $P$, Branchi M, Francucci $B M$, Tiengo $M$. A randomized, within-patient, cross-over, placebo-controlled trial on the efficiency and tolerability of the tricyclic antidepressants chlo rimipramine and nortriptyline in central pain. Act Neurol Scand 1990;82:34-8.

31. Jaegar H, Maier C. Calcitonin in phantom limb pai a double-blind study. Pain 1992;48:21-7.

32. Patterson JF. Carbamazepine in the treatment phantom limb pain. South Med J 1988;81:1100-2

33. Bach S, Noreng MF, Tjéllden NU. Phantom limb pain in amputees during the first 12 months follow ing limb amputation, after preoperative lumbar ep dural blockade. Pain 1988;33:297-301.

34. Nikolajsen L, Ilkjaer S, Christensen JH, Krøner Jensen TS. Randomised trial of epidural bupivacaine and morphine in prevention of stump and phantom pain in lower-limb amputation. Lancet 1997;35ळ 1353-57.

35. Hord AH. Phantom pain. In: Raj PP, editor. Pra tical management of pain. 2nd ed. St. Louis: Moss Year Book, 1992. 